\title{
A Literatura na Intervenção Psicopedagógica
}

\author{
Patrícia dos Santos Pessoa, Márcia Siqueira de Andrade*, Leda Maria \\ Codeço Barone
}

Programa de Psicologia Educacional do Centro Universitário Fieo

* Autora para correspondência: mandrade@unifieo.br

\section{RESUMO}

Este texto tem como objetivo relatar atendimento psicopedagógico de criança com dificuldades de aprendizagem de leitura e escrita, ressaltando a utilização da literatura infantil como possibilidade terapêutica. Trata-se de um estudo de caso que utiliza o método clínico-qualitativo. Descreve-se o atendimento psicopedagógico clínico que teve como instrumento principal a leitura de textos de literatura infantil, a partir da qual se abriram espaços para diferentes formas de atuação terapêutica: diálogos, desenhos, narrativas, entre outras. Os resultados demonstram que a literatura possibilitou situações para a implementação de práticas significativas da escrita e de ressignificação de histórias de sofrimento com essa modalidade de linguagem.

Palavras-Chave: Literatura; Leitura; Aprendizagem; Psicopedagogia.

\begin{abstract}
This paper aims to report a clinical psychopedagogic treatment of children with difficulties in learning to read and write emphasizing the use of children's literature as therapeutic possibility. This is a case study using the clinicalqualitative method. It describes a clinical psychopedagogic treatment which uses, as its main tool, the reading of stories from children's literature from which space opens up for different forms of therapeutic action: dialogue, drawings, narratives amongst others. The results show that the literature created significant practices writing and resignification stories of suffering with this language modality.
\end{abstract}

Keywords: Literature; Reading; Learning; Psychopedagogy.

Pesquisas e opiniões do senso comum apontam dificuldades, por parcela significativa da população brasileira, com relação à apropriação e ao uso da linguagem escrita (GOMES, 2013; ENRICONE \& SALLES, 2011). Ainda que, na maioria dos casos, essas dificuldades tenham sido produzidas por fatores sociais, escolares ou familiares, o fato é que os sintomas de leitura e escrita sugerem que os sujeitos estabelecem uma relação de sofrimento com essa modalidade de linguagem.

Tal realidade está associada à resistência e ao desprazer na relação com a escrita, ao desconhecimento acerca de suas funções, valores e usos, bem como a formas restritas de operar com a leitura e a escrita. Enfim, a relação negativa que os sujeitos estabelecem com a linguagem escrita implica sentimentos de incompetência, de ignorância e de inferioridade que restringem as possibilidades de seu uso (MACHADO, BERBERIAN e SANTANA, 2009).

Nessa direção, o uso da literatura na intervenção psicopedagógica vem sendo apontado como uma abordagem que, potencialmente, favorece a implementação de práticas significativas da linguagem escrita e, portanto, de ressignificação de histórias de sofrimento com essa modalidade de linguagem (BARONE, 2007a; PORCACGHIA \& BARONE, 2011). Levando em conta que os sujeitos com queixa de leitura e de escrita apresentam, muitas vezes, condições de leitura e de escrita consideradas restritas, ao decidir pelo atendimento clínico, identifica-se no processo terapêutico uma possibilidade de ressignificação dos sentidos atribuídos à queixa.

A atividade literária é concebida como uma das formas de elaboração do conflito: da mesma maneira 
que os jogos infantis, a criação de personagens é uma das manifestações de uma função estabilizadora na manutenção da integridade e no desenvolvimento do psiquismo (CRUZ, 2003). Sendo assim, a produção literária é mais autobiográfica do que o próprio escritor chega a reconhecer.

O conflito psíquico pode levar a um processo de fragmentação do aparelho mental, mas também ser um ponto de partida, para um movimento de significação e posterior integração no mundo interno, ao ser transformado em rica, mesmo que dolorosa, experiência de vida (Idem, ibidem). Assim, as personagens e histórias representam o mundo interno construído por emoções, sendo a escrita uma forma de alívio psíquico, na medida em que ajuda o autor a desprender-se da maneira mais absoluta de seus conflitos (Idem, ibidem).

Para Barone, a literatura "é fonte e reservatório de toda a produção humana, em qualquer cultura, e através dela o homem pode tomar consciência de sua realidade, externa e interna [...] oferece ao leitor a forma do humano levando-o a compreender melhor a si e a seu mundo" (2007b, p. 30). Escutar histórias possibilita descobrir o mundo dos conflitos, das dificuldades, dos impasses. É ouvindo histórias que se podem sentir emoções com o significado e verdade que estas fazem brotar (ABRAMOVICH, 2001).

Candido (2004) destaca a importância do fenômeno literário e seus efeitos. Ele diz que a complexidade que advém da natureza se distingue em três faces: a construção de objetos autônomos com a sua estrutura e significado; forma de expressar e manifestar emoções, bem como a visão de mundo tanto individualmente quanto dos grupos; forma de conhecimento.

Diante do exposto, este artigo tem como objetivo relatar atendimento psicopedagógico de criança com dificuldades de aprendizagem de leitura e escrita, ressaltando a utilização da literatura infantil como possibilidade terapêutica.

\section{Método}

Durante o período de agosto a dezembro de 2013 foi realizado o atendimento na Clínica de
Psicopedagogia Unifieo de uma paciente de nove anos a que chamaremos de Ana Clara. No período do atendimento, cursava o terceiro ano do Ensino Fundamental I. Ana Clara foi trazida à clínica pela mãe com queixas de: dificuldades na leitura e escrita, e a escola informou que ela era apenas copista; embora tentasse realizar as atividades, não conseguia evoluir. Ela escrevia corretamente seu nome, mas porque já o memorizara. Reconhecia as vogais e as letras, mas sabia pouco sobre juntar as sílabas.

O primeiro passo para o atendimento foi compreender como a paciente se via diante da situação pela qual foi levada à clínica. Ana Clara tinha dificuldade para falar de si mesma, sentia-se incapaz para a realização de novas tarefas, não acreditava em seu potencial, sentia-se inferiorizada em relação às demais pessoas, não falava muito e era tímida. Demonstrava muito carinho pelas pessoas à sua volta, sentia necessidade de abraçar e beijar, a todo momento gostava de ser elogiada em suas atividades.

Foi marcada uma entrevista com o propósito do levantamento de dados para a anamnese, a fim de que a avaliação e a intervenção pudessem acontecer de maneira adequada e com um olhar mais específico; no horário agendado, a mãe da paciente compareceu à clínica sozinha, dizendo que então não morava com o pai da filha e que se casara novamente.

Foi explicada a ela a importância de uma entrevista com os pais. Ela respondeu a algumas perguntas referentes à filha desde o momento da gestação. Informou que a gravidez foi planejada. Não houve problemas durante a gestação, e tinha o hábito de conversar com o bebê durante a gestação. Ficou sozinha nesse período porque o marido trabalhava longe e retornava para casa somente nos finais de semana. Informou ainda que Ana Clara tinha irmãos por parte de pai, entretanto não havia muito contato entre eles. A mãe só notou a dificuldade da filha depois de ter ido a uma reunião escolar. Procurou a coordenação para que encaminhassem a criança a atendimento psicopedagógico.

Os primeiros atendimentos de Ana Clara se deram por análises de desenhos e busca de com- 
preender como se davam os vínculos de afetividade. Para isso foram utilizados diversos materiais escolares, tais como: lápis, borracha, papéis, canetinhas, e os mais diferentes jogos pedagógicos: dominó, pega-varetas, jogo da dama, xadrez etc.

Durante as sessões de avaliação, foi possível perceber que Ana Clara gostava muito de ouvir histórias e apreciava as leituras, embora tivesse dificuldades quando ela própria devia ler os textos sugeridos durante a atividade. Mas gostava de narrar diversas histórias e entrar no mundo da fantasia.

Baseando-se nessas percepções, durante as sessões de intervenção, o trabalho realizado foi através da literatura em diferentes formas, para que Ana Clara pudesse se sentir mais confiante em si mesma, entrar no mundo da fantasia dos contos e das mais diversas leituras, trabalhando sua percepção, autonomia, leitura e escrita, de modo dinâmico, para que o aprendizado pudesse acontecer de uma maneira lúdica e criativa, levando-a a entender que a aprendizagem é possível. Para isso, ela precisava acreditar em seu potencial e também se esforçar para que seu aprendizado pudesse tornar-se algo eficaz. Ela se mostrava atenta, mas necessitava de estímulos para conseguir alcançar seus objetivos.

As intervenções foram realizadas com a utilização de livros literários tais como: Chapeuzinho Vermelho, João e o Pé de Feijão, Chapeuzinho Amarelo, Branca de Neve, e livros de poesia. A cada semana era trabalhado um livro diferente. Foram feitas várias atividades, desde pinturas, desenhos, colagens, histórias narradas por ela, até a tentativa de escrita. Muitos materiais foram utilizados: papéis coloridos, recortes de revistas, lápis de cor, giz de cera, entre outros.

Algumas sessões foram trabalhadas com pinturas, desenhos, colagens, para que Ana Clara pudesse internalizar as funções lúdicas e para que conseguisse focar a aprendizagem e entender que todas as pessoas passam por dificuldades, mas que é possível crescer como indivíduo.

\section{Discussão}

Vale ressaltar que literatura na clínica de psicopedagogia é possível, ampliando e gerando novas formas de tratamento.
As histórias nos alertam para a responsabilidade de agirmos em determinadas circunstâncias, e, além de todos os estímulos ao imaginário e à criatividade que ouvir uma boa história traz, ouvir histórias favorece o hábito de leitura e por consequência uma boa escrita.

Nesse sentido, a literatura permite um novo olhar acerca da vida, do cotidiano, e faz com que o indivíduo leitor olhe mais para dentro de si mesmo e consequentemente possa acarretar mudanças em sua história, em seus aspectos sociais, em seu mundo interno e externo; ela modifica, renova e promove uma nova caminhada, ainda que inconsciente, rumo à fantasia de que há novas possibilidades e que sonhos podem ser possíveis.

Então, o uso da literatura no atendimento psicopedagógico é de suma importância para a formação de uma pessoa nos mais diversos aspectos, pois através da linguagem o indivíduo deixa de ser apenas um espectador e passa a ser autor de sua própria existência. A linguagem vai mostrando caminhos possíveis para que ele possa trilhar e tornar-se autor de sua própria história. Barone diz: "A literatura desenvolve nossa humanidade na medida em que nos torna mais sensíveis à natureza, à sociedade e ao semelhante" (BARONE, 1993, p. 92). Em especial nesse contexto, a literatura é importante para o desenvolvimento de um sujeito em vários aspectos relacionados à sua existência.

\section{Considerações Finais}

A utilização de literatura infantil foi muito positiva durante a intervenção psicopedagógica, pois representou instrumento principal de auxílio durante as sessões, levando tanto a paciente quanto a psicopedagoga à reflexão sobre a afetividade, os motivos das dificuldades, e para que a intervenção pudesse ser de fato realizada. Os resultados do atendimento foram satisfatórios para a paciente, sua interação com as atividades propostas foi, sem dúvida alguma, muito relevante, e ela foi adquirindo autonomia e se percebendo diante do mundo. O presente trabalho se comprovou relevante, e os resultados satisfatórios, alcançando os principais objetivos, que foram proporcionar à paciente a 
descoberta de sua autonomia.

A literatura mostrou-se importante para a formação de uma pessoa nos mais diversos aspectos, pois através da linguagem o indivíduo deixa de ser apenas um espectador e passa a ser autor de sua própria existência.

\section{Referências Bibliográficas}

ABRAMOVICH, Fanny. Literatura Infantil: Gostosuras e Bobices. 5 ed. São Paulo: Scipione, 2001.

ANDRADE, Márcia Siqueira. Psicopedagogia Clínica: Manual para Diagnóstico. Osasco: Editora Unifieo, 2011.

\& FRANCO, Maria Laura Publissi Barbosa. Aprendizagem Humana. São Paulo: Editora Casa do Psicólogo, 2006.

BARBOSA, Laura Monte Serrat. A Psicopedagogia no Ambito da Instituição Escolar. Curitiba: Expoente, 2001.

BARONE, Leda Maria Codeço. De Ler ao Desejo de Ler. Petrópolis: Vozes, 1993.

. "Literatura e Construção da Identidade". Rev. Psicopedag., São Paulo, vol. 24, n. 74, pp. 110116, 2007a.

"Apontamentos para a Construção do Sujeito Leitor". Constr. Psicopedag., São Paulo, vol. 15, n. 12, pp. 27-37, dez. 2007b.

BOSSA, Nadia A. A Psicopedagogia no Brasil: Contribuições a partir da Prática. Porto Alegre: Artes Médicas, 2000.

CANDIDO, Antonio. "O Direito à Literatura". In: Vários Escritos. Rio de Janeiro: Ouro sobre Azul, 2004.

CRUZ, J. G. "Conflito Psíquico e Criatividade: Alguns Exemplos Colhidos na Literatura". Revista de Psicanálise, vol. 9, pp. 87-97, 2003.

ENRICONE, Jacqueline Raquel Bianchi; SALLES, Jerusa Fumagalli de. "Relação entre Variáveis Psicossociais Familiares e Desempenho em Leitura/Escrita em Crianças". Psicologia Escolar e Educacional, vol. 15, n. 2, pp. 199-210, 2011.

FERNÁNDEZ, Alicia. Os Idiomas do Aprendente. Porto Alegre: Artes Médicas, 2001.
GOMES, Elba Maria Leite. "Avaliação de Língua Portuguesa do Saeb: da Leitura ao Letramento". Estudos em Avaliação Educacional, vol. 17, n. 34, pp. 79-94, 2013.

MACHADO, Maria Letícia Cautela de Almeida; BERBERIAN, Ana Paula \& SANTANA, Ana Paula. "Linguagem Escrita e Subjetividade: Implicações do Trabalho Grupal". Rev. Cefac, São Paulo, vol. 11, n. 4, pp. 713-719, 2009.

MEIRELES, Cecília. Obra Poética. Rio de Janeiro: Aguilar, 1972.

MORIN, Edgar. A Cabeşa Bem Feita: Repensar a Reforma, Repensar o Ensino. 11 ed. Trad. Eloá Jacobina. Rio de Janeiro: Bertrand Brasil, 2005.

PÂNTANO, T \& ZORZI, J. L. Neurociência Aplicada à Aprendizagem. São José dos Campos: Pulso, 2009.

PESSOA, F. Livro do Desassossego. Organização de Richard Zenith. São Paulo: Companhia das Letras, 1999.

PORCACCHIA, Sonia Saj \& BARONE, Leda Maria Codeço. "Construindo Leitores: uma Experiência de Oficina de Leitura". Estud. Psicol. (Campinas), Campinas, vol. 28, n. 3, pp. 395-402, 2011.

PORTO, Olivia. Psicopedagia Institucional: Prática e Assessoramento Psicopedagógico. 3 ed. Rio de Janeiro: Wak Editora, 2009.

SANTOS, Marinalva Batista dos. "Quem é o Psicopedagogo Institucional numa Instituição de Nível Superior?". Disponível em: $<$ http://www.psicopedagogia. com/psicopedagogo-institucional $>$. Acessado em 23 dez. 2010.

SERRA, Daisy, Teorias e Práticas da Psicopedagogia Institucional. Curitiba: IESB, 2004.

VARGAS LLOSA, Mario. El Paraíso en la Otra Esquina. Madrid: Suma de Letras, 2004.

WEISS, Maria Lucia Lemme. Psicopedagogia Clínica: uma Visão Diagnóstica dos Problemas de Aprendizagem Escolar. Rio de Janeiro: DP \& A, 2004.

WOLFFENBUTTEL, Patrícia. Psicopedagogia: Teoria e Prática em Discussão. Novo Hamburgo: Feevale, 2005.

ZIMERMAN, David E. Manual de Técrica Psicanalitica: uma Revisão. Porto Alegre: Artmed, 2004. 